\title{
Construção e validação da Escala de Avaliação da Mediação de Mães de Crianças Pequenas
}

\author{
Celia Vectore - Universidade Federal de Uberlândia ${ }^{1}$ \\ Vanessa Cristina Alvarenga - Universidade Federal de Uberlândia \\ Sinésio Gomide Junior - Universidade Federal de Uberlândia
}

\begin{abstract}
Resumo
O estudo objetivou a construção e validação de uma escala de avaliação de comportamentos mediacionais, observados na interação de mães com seus filhos pequenos (até três anos de idade). Para tanto, foram arrolados 88 itens, oriundos de estudos prévios realizados por um dos autores do presente estudo, sendo submetidos à apreciação de dois juízes, com concordância em 75 dos itens avaliados; os itens foram aglutinados e a escala foi composta por 30 itens. A aplicação consistiu na observação dos comportamentos mediacionais, numa amostra de 300 mães, em momentos de interação com seus filhos. Após a aplicação, foi realizada a análise fatorial dos dados, sendo identificado apenas um fator, composto por 29 itens, resultando na Escala de Avaliação da Mediação de Mães de Crianças Pequenas, que pode ser utilizada em diagnósticos iniciais visando conhecer a qualidade da mediação ofertada pela mãe ao(à) seu(sua) filho(a) pequeno(a).

Palavras-chave: Avaliação psicológica; Mediação; Mães; Crianças pequenas.
\end{abstract}

\section{Construction and validation of an Assessment Scale for Mothers of Young Children}

\begin{abstract}
The aim of this study is the construction and validity of an evaluation scale of mediational behaviours which were observed during interaction between mothers and their young children (up to three years of age). Thus, 88 items from previous studies carried out by one of the authors of the present study were enrolled. They were submitted to evaluation of two judges, who agreed in relation to 75 of the analyzed items; the items were agglutinated and the scale was constituted of 30 items. The application consisted in the observation of mediational behaviours in a sample of 300 mothers during interactions with their children. After the application, factorial data analysis was carried out, and only one factor was identified. This factor was composed of 29 items and resulted in the Mediation between Mothers and Young Children Evaluation Scale, which can be used in initial diagnosis in order to understand the quality of the mediation offered by the mother to her young child.
\end{abstract}

Keywords: Psychological evaluation; Mediation; Mothers; Young children.

\section{Introdução}

O conhecimento e a compreensão dos elementos decisivos relativos a uma adequada interação mãe-criança têm despertado o interesse de estudiosos da psicologia e se constituído em um importante campo de pesquisas e trabalhos, que podem ser constatados pela abrangente literatura internacional e nacional acerca, principalmente, da importância dos primeiros seis anos de vida para $O$ desenvolvimento humano (Ainsworth, Blehar, Walters \& Wall, 1978; Baumrind, 1971; Fonagy, 2001; Goldsmith \& Harman, 1994; Rossetti-Ferreira, Amorim \& Silva, 2000; Thomas \& Chess, 1986). Fatores ligados à globalização, à competição social e à efetiva presença da mulher no mercado de trabalho têm evidenciado, na contemporanei- dade, a necessidade de estudos enfocando tal interação, de modo a subsidiar programas de apoio e políticas públicas voltadas ao atendimento familiar (Rye \& Hundeide, 2005).

Dentro desse contexto, é interessante apontar a criativa contribuição de Fleming (2004), que, numa tentativa de melhor compreender e integrar os aspectos relacionados ao desenvolvimento psicológico, inspirou-se no modelo de dupla hélice da molécula de DNA, elegendo como elementos constituintes da espiral o apego e o processo de separação - individuação, responsáveis pelo curso do desenvolvimento humano. Em contraste com o DNA, menciona que a intensidade entre os dois componentes varia ao longo das diferentes etapas da vida.

Por outro lado, iniciativas como as mencionadas por Tolan e Dodge (2005), realizadas nos Estados Unidos,

\footnotetext{
${ }^{1}$ Endereço para correspondência:

Rua Delmira Cândida Rodrigues da Cunha, 1.279 - Santa Mônica - 38408-208 - Uberlândia-MG

Telefone/Fax: (34) 3219-8693

E-mail: vectore@ufu.br
} 
buscam incrementar propostas preventivas visando à promoção de saúde mental para as crianças, como o oferecimento de serviços culturalmente competentes para as famílias, ou seja, baseados em práticas adequadas ao contexto no qual se inserem (Rogoff, 2003). Em acréscimo, Huang e colaboradores (2005) enfatizam o papel do treinamento, da pesquisa e da prática de intervenções psicológicas na organização de políticas públicas visando ao fomento da saúde mental em crianças e famílias em situação de risco.

Weisz, Sandler, Durlak e Anton (2005) propõem um modelo integrado, oriundo de pesquisas, relacionando$\mathrm{o}$ às atividades de prevenção e intervenção. $\mathrm{O}$ modelo sugere que haja, primeiramente, uma identificação dos programas eficazes, de modo que possam ser adaptados e aplicados em contextos reais, sendo testados em sua eficácia e continuamente ajustados às populações às quais se destinam. Os autores acreditam que conectar a ciência e a prática da prevenção e do tratamento será bom para a ciência, para a prática, para as crianças, para os adolescentes e suas famílias.

Assim, a partir dos estudos desenvolvidos na contemporaneidade, é possível perceber que a promoção de um desenvolvimento humano saudável em todos os seus aspectos está intimamente relacionada ao suporte oferecido às instituições familiares, na construção e manutenção de vínculos estáveis e seguros no contexto familiar. Landry, Smith, Swank, Assel e Vellet (2001) mostraram os efeitos da responsividade materna na predição do desenvolvimento cognitivo e social de crianças, concluindo que os filhos de mães mais responsivas têm um desenvolvimento cognitivo mais acelerado; responsividade foi definida, no estudo, como a construção de um adequado vínculo afetivoemocional entre a díade mãe-criança.

Feldman, Keren, Gross-Rozval e Tyano (2004) e Feldman e Klein (2003), em dois diferentes estudos, mostraram a efetividade dos cuidados dispensados pelos genitores e cuidadores a crianças pequenas no desenvolvimento da cognição e no comportamento social das mesmas. Em outro trabalho, Feldman (2004), demonstrou o efeito positivo do contato pele-a-pele propiciado pelo "cuidado canguru" no desenvolvimento cognitivo das crianças, concluindo que a intervenção canguru fornece indícios de que a proximidade e a separação materna relacionam-se ao desenvolvimento do cérebro, o qual dá origem a uma série de comportamentos exibidos pelas crianças.

No Brasil, iniciativas representadas pelo Referencial Curricular Nacional para a Educação Infantil (1998) e pela inclusão da Educação Infantil na Lei de Diretrizes e Bases da Educação Nacional (Lei 9.394/96), reiteram a importância da primeira infância para $O$ desenvolvimento, quer seja ele realizado prioritariamente em instituições infantis quer junto à família. É interessante observar que a publicação do Fundo das Nações Unidas para a Infância - UNICEF (2005) referente ao relatório Situação da Infância Brasileira 2006 apresenta como tema a ênfase nos primeiros seis anos de vida, recomendando que a principal referência da criança seja a família, porém menciona a importância dos pequenos freqüentarem uma creche de qualidade. Contudo, refere-se que apenas $8 \%$ das crianças até três anos têm acesso a instituições infantis e, entre as crianças de mais de três anos, apenas 57,6\% freqüentam creches ou pré-escolas.

O quadro anteriormente descrito reclama medidas urgentes, no sentido de propiciar novas alternativas que possam contribuir para a formação mais adequada das famílias, tornando-as continente para seus filhos. Uma dessas possibilidades talvez possa ser representada pela adaptação do Programa "Mediational Intervention for Sensitizing Caregivers" ao contexto brasileiro.

O Programa de Intervenção Mediacional para um Cuidador mais Sensível (MISC) trata-se de uma tentativa para definir, avaliar e modificar as variáveis de comportamento dos adultos que se constituem em condições necessárias e suficientes para uma adequada interação entre os mesmos e as crianças (Klein \& Hundeide, 1992). Parte desse programa já foi adaptada às condições brasileiras para a interação mãe-criança (Vectore \& Silva, 1999) e para a interação educadoracriança (Vectore, 2001, 2003), procurando identificar os comportamentos que levam a uma boa mediação.

A partir dos comportamentos identificados por Reuven Feuerstein (1980) e descritos em sua teoria sobre a modificabilidade cognitiva, Klein (1996a, b) enumera cinco comportamentos básicos numa mediação de qualidade, ou seja, a focalização, a expansão, a afetividade, a recompensa e a regulação do comportamento. Assim, a focalização inclui todas as tentativas da mãe para assegurar que a criança focalize a atenção em algo que está ao redor dela. Deve estar clara a indicação da intencionalidade do adulto para mediar e a reciprocidade da criança, a qual é expressa pelas suas respostas verbais ou não-verbais ao comportamento materno.

Por outro lado, a expansão está presente quando a mãe tenta ampliar a compreensão da criança do que está além dos seus sentidos imediatos, utilizando a explicação, a comparação, oferecendo novas experiências além das necessárias para o momento. A afetividade ou mediação do significado refere-se a toda a energia emocional utilizada pela mãe durante a interação com a criança, levando-a a compreender o significado dos objetos, pessoas, relações e eventos ambientais. 
A recompensa é observada quando a mãe expressa satisfação com o comportamento da criança e explica o porquê de estar satisfeita, facilitando sentimentos de autocontrole, de capacidade e sucesso, além de ampliar a sua disponibilidade para explorar ativamente o novo. A regulação do comportamento é identificada quando a mãe ajuda a criança a planejar antes de agir, permitindo que ela se conscientize da adequação do "pensar" antes da ação, planejando os passos do seu comportamento para atingir um objetivo. Atender aos cinco critérios citados implica atingir uma mediação adequada

Klein e Rye (2004) utilizaram os princípios básicos relativos ao comportamento mediacional, adaptando-os e integrando-os dentro da estrutura de práticas tribais de criação de filhos na Etiópia, visando melhorar a qualidade de interações do adulto-criança e, conseqüentemente, promover o potencial de aprendizagem dos pequenos. É interessante observar que, mais de seis anos após a intervenção, as mudanças significativas ocorridas com o procedimento ainda permanecem sendo verificadas tanto na qualidade das interações adulto-criança quanto na performance do desenvolvimento das crianças.

Dessa forma, o objetivo do presente trabalho é construir uma escala de avaliação da mediação, considerando os comportamentos mediacionais já arrolados na literatura relativos às mães de crianças pequenas (até três anos), de modo a se dispor de um material sistematizado na avaliação de tais interações, passível de ser utilizado em investigações futuras. Vale apontar que a construção de instrumentos como o aqui referido permite a implementação de medidas preventivas mais eficazes em um país em desenvolvimento como o Brasil, onde sabidamente é de fundamental importância o apoio dado aos familiares, apresentando os primeiros resultados de uma investigação em contexto brasileiro.

\section{Método}

\section{Elaboração dos itens da escala e validação do conteúdo}

Como primeira etapa de construção da Escala de Avaliação da Mediação de Mães de Crianças Pequenas realizou-se um levantamento bibliográfico de conceitos ligados à mediação, bem como dos critérios mediacionais propostos na literatura pertinente (Klein, 1996a, b), e arrolaram-se os comportamentos mediacionais identificados por Vectore e Silva (1999) num trabalho anteriormente realizado com mães em situação de interação com crianças de zero a três anos. No estudo citado, após a identificação dos comportamentos, procedeu-se à sua classificação, considerando os cinco critérios mediacionais, ou seja, a focalização, a expansão, a afetividade (mediação do significado), a recompensa e a regulação do comportamento.
A seguir, procedeu-se à elaboração de frases que condiziam com o comportamento mediacional, considerando-se os critérios anteriormente mencionados, totalizando 88 itens, sendo 26 referentes à focalização (exemplo: a mãe chama a atenção da criança para um objeto, pessoa, animal ou situação e o nomeia para a mesma); 6 à expansão (exemplo: a mãe nomeia para a criança as roupas e partes do corpo da mesma); 24 à afetividade ou mediação do significado (exemplo: a mãe clarifica para a criança o significado das ações dela - criança, como "você não tá comendo, tá fazendo bagunça".), 10 à recompensa (exemplo: a mãe elogia a criança quando a mesma mostra independência em suas ações, como vestir-se sozinha) e 22 à regulação do comportamento (exemplo: a mãe explica para a criança a conseqüência de um comportamento, como escovar os dentes para não cariálos). Os itens foram elaborados considerando as ações das mães, evitando-se frases que descrevessem aspectos subjetivos e, assim, não diretamente observáveis.

\section{Análise de concordância dos itens}

A lista de itens, composta por 88 comportamentos, foi submetida a três juízas, psicólogas atuantes há mais de quinze anos na área de psicologia do desenvolvimento. A elas foi apresentado, além das definições dos cinco critérios mediacionais, o conjunto dos 88 itens, dispostos aleatoriamente, sendo solicitado que julgassem se um dado item representava, em termos conceituais, algum dos critérios apontados. As juízas avaliaram cada um dos 88 itens, colocando nos parênteses que os sucediam a letra correspondente ao conceito do critério mediacional que eles julgavam representar.

Com as respostas das juízas, foi possível calcular a freqüência de indicação de cada frase constante na lista. Para cada um dos itens foi calculado o Índice de Concordância (IC) entre as juízas. Na seleção dos itens para a construção da Escala de Avaliação da Mediação de Mães de Crianças Pequenas, deveriam ser descartados os itens com IC $<80 \%$ e mantidos os itens com IC $>80 \%$ (Pasquali, 1997, 1999). Entretanto, como os estudos sobre identificação de critérios mediacionais, conforme proposto por Klein (2000) são praticamente inexistentes no Brasil, os pesquisadores optaram por adotar, nesta segunda parte da pesquisa, um IC> ou igual a 67\%, abaixo do índice recomendado pela literatura (Pasquali, 1997, 1999), contudo, compatível com um trabalho de caráter exploratório como este estudo.

Os resultados indicaram que, dos 88 comportamentos mediacionais, $75(85 \%)$ obtiveram índice de concordância maior ou igual a $67 \%$ e $13(15 \%)$ obtiveram índice de concordância abaixo de $67 \%$. 
Tabela 1 - Índice de concordância na avaliação semântica dos juízes e itens resultantes da Escala de Avaliação da Mediação de Mães de Crianças Pequenas

\begin{tabular}{lccc}
\hline Critérios mediacionais & $\mathrm{N}^{\circ}$ de itens iniciais & $\mathrm{N}^{\circ}$ de itens selecionados & Porcentagem \\
\hline Focalização & 26 & 24 & $92 \%$ \\
Expansão & 6 & 4 & $67 \%$ \\
Mediação do significado & 24 & 19 & $79 \%$ \\
Recompensa & 10 & 10 & $100 \%$ \\
Regulação do comportamento & 22 & 18 & $82 \%$ \\
\hline
\end{tabular}

Após a análise das juízas, dos 88 itens iniciais, restaram 75 , os quais foram aglutinados em 30 , de acordo com a sua semelhança semântica, com a finalidade de se ter itens mais bem construídos e com um poder maior de abrangência. Desse modo, a Escala Piloto de Avaliação da Mediação de Mães de Crianças Pequenas que foi submetida à validação foi composta por 30 itens e aplicada em uma amostra de 300 sujeitos (10 sujeitos por item). Os dados obtidos nessa aplicação permitiram verificar a validade fatorial da Escala de Avaliação da Mediação de Mães de
Crianças Pequenas.

\section{Estudo para validação de conteúdo}

\section{Participantes}

Participaram do estudo 300 mães, que foram observadas durante momentos de interação com seus filhos pequenos (zero a três anos). A média de idade das mães foi de 28 anos, sendo a maioria casada $(65,7 \%)$ e com o $2^{\circ}$ grau completo (54\%), conforme pode ser verificado na Tabela 2 .

Tabela 2 - Dados demográficos das mães participantes $(\mathrm{n}=300)$

\begin{tabular}{cccc}
\hline Variável & Nível & Freqüência & Porcentagem \\
\hline Idade (anos) & $15-20$ & 22 & $7,3 \%$ \\
& $21-30$ & 200 & $66,7 \%$ \\
& $31-40$ & 67 & $22,3 \%$ \\
& $41-50$ & 10 & $3,3 \%$ \\
& $51-53$ & 01 & $0,3 \%$ \\
\hline Estado civil & Solteira & 70 & $23,3 \%$ \\
& Casada & 197 & $65,7 \%$ \\
& Outro & 33 & $11 \%$ \\
\hline Grau de instrução & $1^{\circ}$ grau completo & 81 & $27 \%$ \\
& $2^{\text {o }}$ grau completo & 162 & $54 \%$ \\
& $3^{\circ}$ grau completo & 57 & $19 \%$ \\
\hline
\end{tabular}

A média de idade das crianças foi de 21 meses, sendo 154 (51,3\%) do sexo masculino e 146 (48,7\%) do sexo feminino.

\section{Instrumento}

\section{Escala de Avaliação da Mediação de Mães de Crianças Pequenas}

A Escala de Avaliação da Mediação de Mães de Crianças Pequenas elaborada pelos autores do presente texto e submetida à validação tratou-se de um instrumento com o objetivo de permitir a avaliação de comportamentos mediacionais, observados na interação das mães com seus filhos pequenos (até 3 anos) em diferentes atividades de rotina. Foi composta por 30 itens, englobando os critérios mediacionais denominados: focalização (8 itens); expansão (3 itens); mediação do significado (3 itens); recompensa (5 itens); regulação do comportamento (11 itens). As freqüências variaram de um (1) a quatro (4), sendo: 1) o comportamento apontado nunca ocorre; 2) o comportamento apontado ocorre poucas vezes; 3) o comportamento apontado ocorre muitas vezes e 4) o comportamento apontado ocorre sempre. É interessante observar que em procedimento semelhante já foi elaborada a Escala Mediacional de Educadores Infantis (Vectore, Alvarenga \& Gomide, 2006).

Para a aplicação do instrumento foram recrutados oito alunos do curso de Psicologia da Universidade Federal de Uberlândia, os quais foram devidamente treinados para a realização das observações em domicilio, o que os capacitou a atuar como auxiliares de pesquisa na coleta de dados. Eles foram até a casa das mães, a fim de explicar o trabalho, obter a autorização para a pesquisa e agendar as visitas. O endereço das famílias, na maioria dos casos, foi fornecido pelas creches municipais da cidade de Uberlândia, Minas Gerais, cujas coordenadoras foram contatadas e se dispuseram a auxiliar, entregando às mães um bilhete, com a explicação do estudo e um convite para participação. 
Os observadores ficaram, em média, de três a quatro horas com cada mãe, a fim de observar os comportamentos descritos na escala, anotando a freqüência em que ocorriam. Foi pedido também aos observadores que fizessem um registro cursivo de cada situação observada, de modo a poder dirimir qualquer dúvida na marcação da freqüência do comportamento observado. É interessante apontar que o cômputo geral das horas observadas, considerando todas as díades, correspondeu a cerca de 1.000 horas de observação. Após a aplicação do instrumento, foram feitos os cálculos estatísticos e a análise fatorial.

\section{Resultados e discussão}

A análise fatorial (PAF), método oblimin, definindo-se como carga fatorial mínima o valor de 0,30 para retenção do item, apontou a existência de um agrupamento consistente de itens com eigenvalues superiores a 11,0 explicando $38,13 \%$ da variância total. O fator consistente foi analisado para a identificação semântica, conforme proposto pelo programa de treinamento MISC. O fator obteve índice de precisão de 0,95 .

Com essa configuração, a Escala de Avaliação da Mediação de Mães de Crianças Pequenas ficou constituída por um fator representado por 29 itens com carga fatorial entre 0,37 e 0,74, compondo os comportamentos básicos numa mediação. A Tabela 3 apresenta os resultados referentes aos 29 itens do fator único.

O fator único, denominado mediação de mães de crianças pequenas, congrega um conjunto de itens referentes aos cinco comportamentos básicos numa mediação, que são: focalização, expansão, mediação do significado, recompensa e regulação do comportamento.

Tabela 3 - Carga fatorial (CF), descrição e comunalidade $\left(\mathrm{h}^{2}\right)$ dos itens integrantes do fator 1 - Escala de Avaliação da Mediação de Mães de Crianças Pequenas

\begin{tabular}{ccc}
\hline Ordem & Item & CF \\
\hline 1 & 1 & 0,60 \\
& & \\
2 & 2 & 0,45 \\
3 & 3 & 0,71 \\
& & \\
4 & 4 & 0,64 \\
5 & 5 & 0,67 \\
6 & 6 & 0,62 \\
7 & 7 & 0,61 \\
& & \\
8 & 8 & 0,63 \\
9 & 9 & 0,56 \\
10 & 10 & 0,37 \\
& & \\
11 & 11 & 0,70 \\
& & \\
12 & 12 & 0,60 \\
13 & 13 & 0,40 \\
14 & 14 & 0,68 \\
15 & 15 & 0,73 \\
& & \\
16 & 16 & 0,69 \\
17 & 17 & 0,71 \\
18 & 18 & 0,58 \\
19 & 19 & 0,64 \\
20 & 21 & 0,57
\end{tabular}

Descriç̃o

Descrição
continua...

A mãe explica para a criança uma seqüência de ações (ex: primeiro tomar banho $\quad$ 0,36 e depois comer o iorgute).

A mãe chama a atenção da criança para um objeto, pessoa, animal ou situação e $\quad 0,21$ o nomeia para a mesma.

A mãe explica para a criança a conseqüência de um comportamento (ex: escovar 0,51 os dentes para não cariá-los; água quente queima).

A criança reconhece algo e a mãe a elogia. $\quad 0,41$

A mãe nega algo para a criança e explica o porquê de sua ação. $\quad 0,45$

A mãe ensina algo para a criança (ex: as cores da caneta).

0,38

A mãe clarifica para a criança o significado das ações dela (criança) (ex: "Você $\quad 0,37$ não tá comendo, tá fazendo bagunça").

A criança faz alguma atividade e a mãe a incentiva.

A mãe nomeia para a criança as roupas e partes do corpo da mesma. $\quad 0,32$

A mãe fala com a criança e demonstra, por meio de gestos afetuosos, o seu $\quad 0,14$ carinho por ela.

A mãe explica para a criança o motivo pelo qual ela não poderá realizar uma $\quad 0,50$ atividade (ex: tomar sorvete, pois está gripada).

A mãe diz para a criança não mexer no que não é seu (da criança). $\quad$ 0,36

A mãe demonstra sua irritação com a criança, por meio de gestos e palavras. $\quad 0,16$

A mãe demonstra para a criança como se faz algo e ela a imita. $\quad 0,46$

A mãe sugere para a criança determinado comportamento e explica por que a $\quad 0,53$

mesma deve emiti-lo (ex: tirar a roupa molhada, porque pode ficar doente).

A mãe chama a criança para ajudá-la em uma atividade e a elogia quando o faz $\quad 0,48$ corretamente.

A mãe elogia a criança quando a mesma mostra independência em suas ações $\quad 0,50$ (ex: vestir-se sozinha).

A mãe demonstra para a criança como se faz para brincar com o brinquedo. $\quad 0,34$

A mãe explica algo para a criança, a fim de se fazer entendida. $\quad 0,41$

A mãe quando alimenta a criança, nomeia os utensílios e a comida para a $\quad 0,32$ mesma. 
Tabela 3 - Carga fatorial (CF), descrição e comunalidade $\left(h^{2}\right)$ dos itens integrantes do fator 1 - Escala de Avaliação da Mediação de Mães de Crianças Pequenas conclusão...

\begin{tabular}{|c|c|c|c|c|}
\hline 21 & 22 & 0,52 & A mãe dá significado à fala da criança (ex: "Me chamou de mamãe, meu amor"). & 0,28 \\
\hline 22 & 23 & 0,60 & $\begin{array}{l}\text { A mãe reforça com elogios os comportamentos adequados emitidos pela criança } \\
\text { no seu relacionamento com ela. }\end{array}$ & 0,36 \\
\hline 23 & 24 & 0,51 & A mãe negocia com a criança a troca de algo desejado por outra coisa. & 0,26 \\
\hline 24 & 25 & 0,58 & $\begin{array}{c}\text { A mãe tenta organizar as atividades da criança, localizando-as no tempo e no } \\
\text { espaço (ex: a criança diz que quer mamar. "Daqui a pouco, pois você almoçou } \\
\text { agora mesmo"). }\end{array}$ & 0,33 \\
\hline 25 & 26 & 0,69 & $\begin{array}{c}\text { A mãe corrige a fala da criança, apresentando-lhe o modo correto, porém sem } \\
\text { enfatizar o seu erro. }\end{array}$ & 0,48 \\
\hline 26 & 27 & 0,65 & A mãe explica para a criança o modo como deve se comportar. & 0,42 \\
\hline 27 & 28 & 0,73 & $\begin{array}{l}\text { A mãe demonstra para a criança uma seqüência de ações, a fim de que a mesma } \\
\text { alcance o objetivo desejado (ex: "Você tem que abrir primeiro a lata, para depois } \\
\text { pegar a bolacha"). }\end{array}$ & 0,54 \\
\hline 28 & 29 & 0,67 & A mãe chama a criança para fazer uma atividade, como, por exemplo, escrever. & 0,46 \\
\hline 29 & 30 & 0,74 & $\begin{array}{l}\text { A mãe ajuda a criança a fazer algo corretamente, falando e mostrando para a } \\
\text { criança como se faz. }\end{array}$ & 0,55 \\
\hline
\end{tabular}

Seria esperado, a partir da perspectiva teórica selecionada (Programa MISC), que se obtivessem cinco fatores que agrupassem itens referentes aos critérios mediacionais - focalização, expansão, mediação do significado, recompensa e regulação do comportamento contudo, isso não foi constatado. O que se obteve foi um grupo de comportamentos mediacionais formados por diferentes critérios exibidos durante as atividades de rotina entre mães e crianças pequenas, que são freqüentes em grande parte dos lares brasileiros, constituído por estratos socioeconômicos menos favorecidos. Assim, as atividades se distribuem prioritariamente entre cuidados físicos com a criança, representados pela alimentação, higiene e normas de conduta, visando à regulação de seu comportamento.

É interessante apontar que raríssimas vezes foram observados comportamentos visando um enriquecimento cognitivo da criança, como os previstos nas atividades de expansão, que possibilita ao mediador buscar outras experiências que não as presentes no momento, a fim de ampliar a compreensão do mediado. Assim, se o mediador não dispõe de informações cognitivas para tal, certamente esse critério não estará tão disponível à díade mediadormediado e, além disso, considerando que o desenvolvimento cognitivo está atrelado ao desenvolvimento cerebral, o qual ocorre por meio de "um processo plástico programado por genes e esculpido pela experiência" (Yudofsky \& Hales, 2006, p. 903), pode-se supor que interações desprovidas de estimulações adequadas não otimizem esse neurodesenvolvimento.

Os dados do presente estudo corroboram os achados de Vectore e Silva (1999), no que diz respeito à incipiência das mediações maternas, que talvez possam ser explicadas pela dificuldade e desconhecimento das mães pesquisadas em utilizar as situações o dia-a-dia como estratégias para o desenvolvimento infantil, desafiando seus filhos para novos conhecimentos. Nesse sentido, é importante ressaltar que, embora os padrões mediacionais da amostra estudada contemplem poucas atividades de expansão e mediação de significados, isso não impossibilita a aplicação do programa MISC, pois o mesmo deve se iniciar pelas atividades que são mais freqüentes na população avaliada. Portanto, no caso em questão, foram mais freqüentes as atividades ligadas à regulação do comportamento.

\section{Considerações finais}

$\mathrm{O}$ presente trabalho, embora tenha atingido o objetivo de validação de um instrumento de medida de avaliação da mediação de mães de crianças pequenas com índice de precisão de 0,95 , podendo ser utilizado em situações de avaliação inicial em contextos semelhantes ao investigado, ou seja, antes de se propor intervenções mais direcionadas, relativas à identificação de comportamentos mediacionais de mães, suscitou alguns questionamentos. $\mathrm{O}$ primeiro deles diz respeito ao agrupamento dos itens. Estes foram agrupados num só fator, representado por comportamentos mediacionais, apresentando itens referentes aos cinco comportamentos básicos previstos numa mediação de qualidade, que são: focalização; expansão; mediação do significado; recompensa e regulação do comportamento. Contudo, esperava-se obter cinco fatores que agrupassem itens referentes aos comportamentos básicos numa mediação, conforme proposto pela teoria que embasa o programa MISC, o que não ocorreu na prática.

Uma possível resposta ao primeiro questionamento apontado pode ser dada em virtude da dificuldade de se transpor conceitos elaborados em um contexto 
cultural e socioeconômico diverso da realidade brasileira, embora valha a pena afirmar que todos os comportamentos avaliados partiram de um enquadre nacional, o que, sem dúvida, fortalece a pertinência do instrumento. Um outro questionamento refere-se à necessidade de novos estudos sobre a teoria que fundamentou a pesquisa, de modo que a mesma possa produzir dados, investigando outras regiões do país, tornando cada vez mais consistente a sua aplicação em território brasileiro.

Feitas tais ressalvas, acredita-se que o presente instrumento é passível de ser utilizado em situações em que o conhecimento do perfil mediacional, representado pelo modo como a mãe interage com o seu filho, constitua-se de fundamental importância para a consecução de medidas efetivas de intervenção. Portanto, acredita-se que, por meio da escala ora apresentada, seja possível avaliar, de forma relativamente rápida e segura, aspectos da interação mãe-criança que devem ser priorizados na proposição de práticas condizentes com o padrão mediacional das mães brasileiras.

\section{Referências}

Ainsworth, M. D. S., Blehar, M. C., Walters, E. \& Wall, S. (1978). Patterns of attachment: A psychological study of the Strange Situation. Hillsdale, NJ: Erlbaum.

Baumrind, D. (1971). Current patterns of parental authority. Developmental Psychology Monographs, 4, 1-103.

Feldman, R. (2004). Mother-infant skin-to-skin contact (Kangaroo Care): Theoretical, clinical, and empirical aspects. Infants \& Young Cbildren, 17(2), 145-161.

Feldman, R. \& Klein, P. S. (2003). Toddlers' self-regulated compliance to mothers, caregivers, and fathers: Implications for theories of socialization. Developmental Psycbology, 39, 680-692.

Feldman, R., Keren, M., Gross-Rozval, O. \& Tyano, S. (2004). Mother-child touch patterns in infant feeding disorders: relation to maternal, child, and environmental factors. Journal of the American Academy of Child \& Adolescent Psychiatry, 43(9), 1089-1097.

Feuerstein, R. (1980). Instrumental enricbment: Redevelopment of cognitive functions of retarded performers. New York: University Park Press.

Fleming, M. (2004). A double helix model for human psychological development. EJCP, 7. Obtido em 12 de dezembro de 2005 do World Wide Web: http://www.scielo. br/.

Fonagy, P. (2001). Attachment theory and psychoanalysis. New York: Other Press.
Fundo das Nações Unidas para a Infância - UNICEF (2005). Relatório da situação da infância brasileira - 2006. Obtido em 16 de dezembro de 2005 do World Wide Web: http://www.unicef.org.br/.

Goldsmith, H. H. \& Harman, C. (1994). Temperament and attachment; individuals and relationships. Current Directions in Psychological Science, 3, 53-61.

Huang, L., Stroul, B., Friedman, R., Mrazek, P., Friesen, B. \& Pires, S. (2005). Transforming mental health care for children and families. American Psychologist, 60(6), 615-627.

Klein, P. S. (1996a). Early intervention: cross-cultural experiences with a mendiational approach. New York: Garland.

Klein, P. S. (1996b). Early childhood education: Seventy-first yearbook of the National Society for the Study of Education. Chicago: University of Chicago Press.

Klein, P. S. (2000). A developmental mediation approach to early intervention: Mediational Intervention for Sensitizing Caregivers (MISC). Educational \& Child Psychology, 17(3), 19-31.

Klein, P. S. \& Hundeide, K. (1992). Mediated learning experiences and at-risk children. Em L. R. Williams \& D. P. Fromberg (Orgs.). Encyclopedia of early childhood education (p. 241). New York: Garland.

Klein, P. S. \& Rye, H. (2004). Interaction-oriented early intervention in Ethiopia: The MISC approach. Infants \& Young Children, 17(4), 340-354.

Landry, S. H., Smith K. E., Swank, P. R., Assel, M. A. \& Vellet, S. (2001). Does early responsive parenting have a special importance for children's development or is consistency across early childhood necessary? Developmental Psycholology, 37(3), 387-403.

Lei de Diretrizes e Bases da Educação Nacional (1996). Lei $n^{\circ}$. 9.394/96, de 20/12/96. Brasília, DF: Ministério da Educação.

Pasquali, L. (1999) (Org.). Instrumentos psicologicos: manual prático de elaboração. Brasília: LABPAM/IBAPP.

Pasquali, L. (1997). Psicometria: teoria e aplicaçoes. Brasília: Editora da UnB.

Referencial Curricular Nacional para a Educação Infantil. (1998). Brasília, DF: Ministério da Educação.

Rogoff, B. (2003). The cultural nature of child development. Cambridge: Cambridge University Press.

Rossetti-Ferreira, M. C., Amorim, K. S. \& Silva, A. P. S. (2000). Uma perspectiva teórico-metodológica para análise do desenvolvimento humano e do processo de investigação. Psicologia: Reflexão e Crítica, 13(2), 281-293. 
Rye, H. \& Hundeide, K. (2005). Early intervention and children with special needs in developing countries. Em M. Guralnick (Org.). The developmental systems approach to early intervention (pp. 593-620). New York: Brookes Publishing.

Thomas, A. \& Chess, S. (1986). The New York longitudinal study: From infancy to early adult life. Em R. Plomin \& J. Dunn (Orgs.). The study of temperament: Changes, continuities, and challenges (pp. 39-52). Hillsdale, NJ: Erlbaum.

Tolan, P. H. \& Dodge, K. A. (2005). Children's mental health as a primary care and concern: A system for comprehensive support and service. American Psychologist, 60(6), 601-614.

Vectore, C. (2001). Adaptação e possibilidades de utilização do programa MISC - "Mediational Intervention for Sensitizing Caregivers" na formação continuada de professores de educação infantil. Relatório de Pesquisa de Pós-Doutorado. São Paulo: Universidade de São Paulo.

Vectore, C. (2003). O brincar e a intervenção mediacional na formação continuada de professores de educação infantil. Psicologia USP, 14(3), 105-131.
Vectore, C. \& Silva, C. E. (1999). Adaptação do programa MISC - Mediational Intervention for Sensitizing Caregivers - numa população brasileira de baixa renda. Texto \& Contexto, 8(2), 445-448.

Vectore, C., Alvarenga, V. C. \& Gomide, S. (2006). Construção e validação de uma escala de comportamentos mediacionais de educadores infantis. Psicologia Escolar e Educacional, 10(1), 53-68.

Weisz, J. R., Sandler, I. N., Durlak, J. A. \& Anton, B. S. (2005). Promoting and protecting youth mental health through evidence-based prevention and treatment. American Psychologist, 60(6), 628-648.

Yudofsky, S. C. \& Hales, R. E. (2006). Neuropsiquiatria e neurociências na prática clinica $\left(4^{\mathrm{a}} \mathrm{ed}\right)$. Porto Alegre: Artmed.

Recebido em fevereiro de 2006 Reformulado em junho de 2007 Aprovado em agosto de 2007

Sobre os autores:

Celia Vectore é graduada em Psicologia, com Mestrado, Doutorado e Pós-Doutorado em Psicologia Escolar pela Universidade de São Paulo e Università degli Studi di Ferrara, Itália. Atualmente é professora associada da Universidade Federal de Uberlândia. Tem experiência na área de Psicologia, com ênfase em Psicologia do Desenvolvimento e Aprendizagem, atuando principalmente nos seguintes temas: desenvolvimento humano e educação infantil.

Sinésio Gomide Júnior é graduado em Psicologia, com Mestrado e Doutorado em Psicologia pela Universidade de Brasília. Atualmente é professor associado da Universidade Federal de Uberlândia. Tem experiência na área de Psicologia, com ênfase em Psicologia do Trabalho e Organizacional, atuando principalmente nos seguintes temas: comportamento organizacional, psicometria, bem-estar no trabalho e recursos humanos.

Vanessa Cristina Alvarenga é graduada em Psicologia pela Universidade Federal de Uberlândia. Foi bolsista do PIBIC/CNPq/UFU. Atualmente é mestranda no Programa de Educação Escolar junto à Unesp, câmpus Araraquara. 